\title{
EFISIENSI SALURAN PEMASARAN DURIAN (Durio zibethinus) DI DESA MLANCU KECAMATAN KANDANGAN KABUPATEN KEDIRI
}

\author{
Siti Nur Kholifah ${ }^{1}$ Dyah Ayu Sri Hartanti ${ }^{2}$, Elina Sabat ${ }^{3}$, \\ Program Studi Agribisnis, Fakultas Pertanian, Universitas KH A Wahab Hasbullah \\ oliplip4@gmail.com
}

\begin{abstract}
ABSTRAK
Penelitian ini bertujuan untuk mengetahui Farmer's Share, Marjin Pemasaran dan Efisiensi Pemasaran durian di Desa Mlancu Kecamatan Kandangan Kabupaten Kediri. Metode penelitian dan pengumpulan data pada penelitian ini adalah survey, observasi dan wawancara pada 178 antara lain petani, pedagang, tengkulak, penebas menjadi responden. Penelitian ini dilaksanakan pada bulan Oktober-November 2019. Saluran pemasaran durian di Desa Mlancu Kecamatan Kandangan Kabupaten Kediri terdapat IV saluran pemasaran. Saluran pemasaran paling banyak di lakukan oleh petani dan lembaga pemasaran adalah saluran II yaitu sebanyak 85 orang atau $47,7 \%$, kemudian pada saluran III sebanyak 45 orang atau $25,3 \%$ diikuti pola IV sebanyak 22 orang atau $12,4 \%$ dan 26 orang pada saluran pemasaran I atau 14,6\%. Nilai farmer's share yang diperoleh pada saluran pemasaran I 100\%, saluran pemasaran II sebesar $71,4 \%$, saluran pemasaran III sebesar $62,5 \%$, dan saluran pemasaran IV sebesar $33,3 \%$. Pada nilai marjin pemasaran, saluran pemasaran I tidak adanya marjin pemasaran dikarenakan petani langsung memasarkan durian kepada konsumen, sehingga tidak ada lembaga pemasaran yang terlibat. Sedangkan margin pemasaran pada saluran ke II sebesar Rp $10.000,00$ / buah, saluran pemasaran III Rp15.000,00/ buah dan saluran pemasaran yang ke IV sebesar Rp 30.000,00/ buah. Saluran pemasaran durian di Desa Mlancu Kecamatan Kandangan Kabupaten Kediri sudah efisien.
\end{abstract}

Kata Kunci: Durian, Efisiensi Pemasaran, Farmer's Share, Marjin Pemasaran, Saluran Pemasaran.

\section{PENDAHULUAN}

Buah buahan merupakan salah satu komoditas hortikultura yang mempunyai nilai ekonomi tinggi yang dapat menjadi sumber pendapatan bagi masyarakat dan petani baik berskala kecil, menengah maupun besar, karena memiliki keunggulan berupa nilai jual yang tinggi, keragaman jenis, ketersediaan sumberdaya lahan dan teknologi, serta potensi serapan pasar di dalam negeri dan internasional yang terus meningkat. Subsektor yang saat ini tengah dikembangkan yakni subsektor hortikultura, hal ini karena hortikultura merupakan bagian dari pembangunan pertanian dibidang pangan yang ditujukan untuk lebih memantapkan swasembada pangan, meningkatkan pendapatan masyarakat dan memperbaiki keadaan gizi melalui penganekaragaman jenis bahan makanan (Kementerian Pertanian Ditjen Hortikultura, 2013).

Nama durian diambil dari ciri khas kulit buahnya yang keras dan berlekuk-lekuk tajam sehingga menyerupai duri, sehingga durian juga dikenal dengan sebutan "raja dari segala buah" (Kingof Fruit). Upaya peningkatan produksi buah bermutu dalam jumlah yang mencukupi dapat dilakukan denganpeningkatan populasi tanaman buah serta peningkatan teknologi budidaya yang dilakukan. Selain itu guna menjamin produk buah yang aman dikonsumsi perlu dilakukan teknologi budidaya yang memperhatikan kelestarian lingkungan sesuai dengan SOP (Standart Operating Procedure) dan konsep budidaya Good Agriculture Practice (GAP), (Dinas Pertanian Yogyakarta, 2012). 
SigmAgri (Journal of Social, Management, and Agribusiness)

Volume 01 No 01

Tabel 1. Keadaan Penduduk Menurut Mata Pencaharian di Desa Mlancu Tahun 2019

\begin{tabular}{llcc}
\hline No & Mata Pencaharian & Jumlah & $\%$ \\
\hline 1 & Petani & 2.508 & 48,8 \\
2 & Pedagang & 377 & 7,3 \\
3 & Peternak & 1.115 & 21,6 \\
4 & PNS & 18 & 0,3 \\
5 & TNI/Polri & 11 & 0,2 \\
6 & Pengrajin & 8 & 0,1 \\
7 & Lain-lain & 1.102 & 21,7 \\
\hline Jumlah & & 5.139 & 100 \\
\hline
\end{tabular}

Sumber : Data Desa Mlancu, 2019

Berdasarkan Tabel 1. dapat diketahui bahwa penduduk di Desa Mlancu yang bekerja di sektor pertanian yaitu sebanyak $48,8 \%$. Hal ini menunjukkan bahwa sektor pertanian mempunyai peranan yang cukup penting bagi Desa Mlancu dalam hal penyerapan tenaga kerja di sektor pertanian. Sebagian besar penduduk Desa Mlancu bermata pencaharian sebagai petani. Hal ini sebabkan karena lahan dan iklim di Desa Mlancu cocok untuk berbagai macam lanaman pangan dan buah.

Pemasaran merupakan salah situ faktor terpenting ketika produsen/petani telah dapat menghasilkan produk yang meıniliki kualitas dan kuantitas yang baik. Pemasaran merupakan suatu sistem dari suatı kegiatan yang ditujukan untuk merencanakan, menentukan harga, mempromosikan serta mendistribusikan barang yang telah diproduksi untuk bisa sampai ke tangan konsumen, baik konsumen akhir maupun konsumen yang potensial dimana barang tersebut untuk dijual kembali. Semua keputusan yang diambil pada proses pemasaran harus ditujukan untuk menentukan produk, pasar, harga, promosi dan sistem produksinya (Pasaribu, 2012).

Tinggi rendahnya efisiensi saluran pemasaran juga ikut mempengaruhi harga di tangan petani Selain faktor penawaran dan permintaan. Saluran pemasaran yang dilakukan semakin pendek maka akan semakin tinggi pula harga suatu produk tersebut di tangan petani, sedangkan semakin panjang rantai saluran pemasaran maka harga di tangan petani akan semakin rendah. Efisiensi saluran pemasaran juga perlu diketahui sampai seberapa besar margin dari sebuah saluran pemasaran dapat dinikmati oleh petani, selain berdasarkan ukuran teknis panjang pendeknya saluran pemasaran. Saluran pemasaran dapat dikatakan efisien secara ekonomis jika total keuntungan yang diambil oleh pedagang relatif lebih kesil terhadap biaya pemasaran (Muslim dan Darwis, 2012). Penelitian ini bertujuan untuk menganalisis saluran pemasaran, marjin pemasaran, farmer's share dan efisiensi durian di Desa Mlancu Kecamatan Kandangan Kabupaten Kediri.

\section{METODE PENELITIAN}

Penelitian di lakukan pada tah un 2019 dengan lokasi survay di Desa Mlancu Kecamatan Kandangan Kabupaten Kediri. Data terdiri dari data primer dan data sekunder, data primer diperoleh dari hasil wawancara dengan kuesioner terhadap responden. Data sekunder diperoleh dari instansi terkait, baik ditingkat pusat maupun daerah.

\section{Analisis Data}

Pada bagian efisiensi digunakan perhitungan Farmer's Share untuk melihat harga yang terjadi pada setiap rantai pemasaran. Marjin pemasaran merupakan selisih harga ditingkat konsumen dan harga ditinggkat produsen. Pada bagian efisiensi akan dibahas mengenai indeks efisiensi teknis dan ekonomi

\section{Farmer's Share}

Farmer's share persentase perbandingan antara bagian harga yang diterima oleh petani dengan bagian harga di konsumen akhir. Farmer Share antara komoditi yang satu dengan komoditi yang lain berbeda, hal ini tergantung dari jumlah kegunaan bentuk, 


\section{SigmAgri (Journal of Social, Management, and Agribusiness)}

Volume 01 No 01

tempat dan waktu yang ditambahkan oleh petani dan pedagang perantara yang terhubung dalam suatu saluran pemasaran (Tjiptono, 2014)

Farmer share $(\mathrm{FS})=\frac{p f}{p r} \times 100 \%$.

Dimana FS adalah Farmer share atau bagian harga yang diterima petani Duriandalam persentase (\%), Pf adalah harga pembelian di tingkat petani (Rp/buah), $\mathrm{Pr}$ adalah harga eceran di tingkat konsumen (Rp/ buah).

\section{Marjin Pemasaran}

Menurut Widiastuti dan Harisudin (2013) untuk menghitung marjin dari setiap lembaga pemasaran digunakan rumus :

$\mathrm{Mp}=\mathrm{Pr}-\mathrm{Pf}$

$\mathrm{Mp}=\mathrm{Bp}+\mathrm{Kp}$

Dimana $\mathrm{Mp}$ adalah Marjin pemasaran ( $\mathrm{Rp} /$ buah), $\mathrm{Pr}$ adalah harga ditingkat konsumen (Rp/ buah), Pf adalah Harga ditingkat produsen ( $\mathrm{Rp} / \mathrm{buah}$ ), Bp adalah biaya Pemasaran ( $\mathrm{Rp} /$ buah) dan Kp adalah keuntungan Pemasaran ( $\mathrm{Rp} / \mathrm{buah})$.

Hammond dan Dahl (dalam Abidin, 2015) menyatakan bahwa marjin pemasaran menggambarkan perbedaan harga di tingkat konsumen $(\mathrm{Pr})$ dengan harga di tingkat produsen (Pf). Setiap lembaga pemasaran melakukan fungsi-fungsi pemasaran yang berbeda sehingga menyebabkan perbedaan harga jual dari lembaga satu dengan yang lainnya sampai ke tingkat konsumen akhir. Semakin banyak lembaga pemasaran yang terlibat semakin besar perbedaan harga antar produsen dengan harga di tingkat konsumen.

\section{Efisiensi Pemasaran}

Menurut Roesmawaty (2011), efisiensi pemasaran dapat dihitung dengan menggunakan rumus berikut :

$\mathrm{EP}=\frac{T B \times 100 \%}{T N P}$

Dimana EP adalah Efisiensi pemasaran (\%), TB adalah total biaya pemasaran (Rp), TNP adalah total nilai produk (buah). ), saluran pemasaran bisa dikatakan efisien apabila, persentase Efisiensi Pemasaran (EP) sebesar $>50 \%$ maka saluran pemasaran dikatakan efisien, dan bila EP $\leq 50 \%$ maka saluran pemasaran kurang efisien.

\section{HASIL DAN PEMBAHASAN}

\section{Pemasaran Durian}

Kegiatan pemasaran durian ke konsumen memerlukan adanya pedagang perantara atau yang disebut juga sebagai lembaga pemasaran yang mempunyai peranan penting dalam kegiatan pemasaran. Lembaga pemasaran yang terlibat dalam pemasaran durian di Desa Mlancu Kecamatan Kandangan Kabupaten Kediri meliputi penebas, tengkulak, pedagang.

\section{Saluran Pemasaran}

Saluran pemasaran durian di Desa Mlancu Kecamatan Kandangan Kabupaten Kediri untuk sampai konsumen terlihat pada Gambar 1

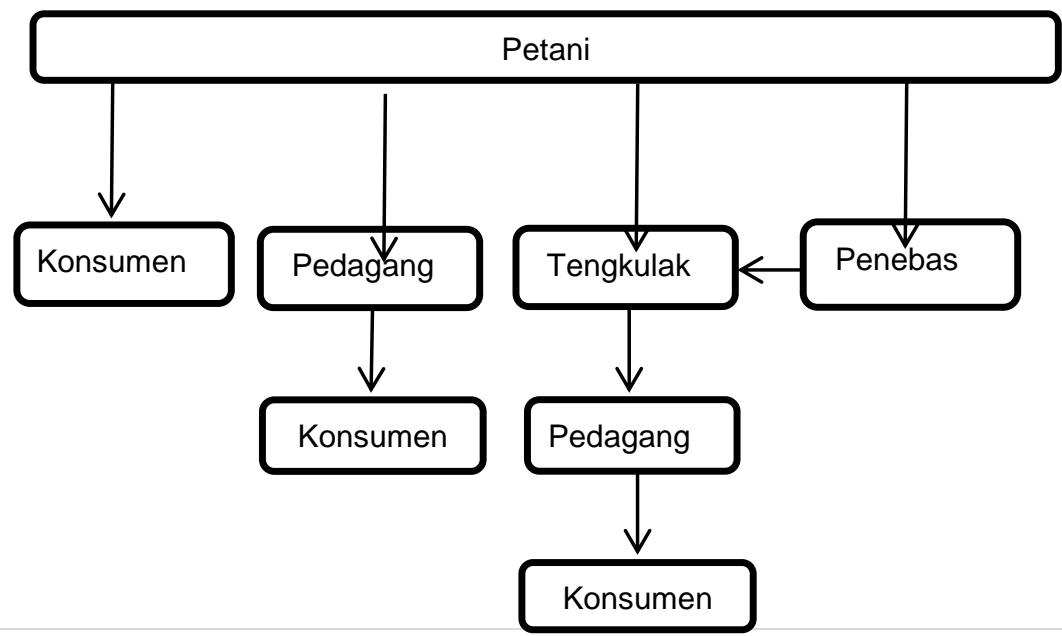


Gambar. 1 Saluran Pemasaran Durian di Desa Mlancu Sumber: Data primer yang diolah, 2019

Berdasarkan Gambar 1 dapat diketahui pola saluran pemasaran durian di Desa Mlancu Kecamatan Kandangan Kabupaten Kediri ada empat yaitu:

1. Saluran I : petani $\rightarrow$ konsumen.

2. Saluran II : Petani $\rightarrow$ pedagang $\rightarrow$ konsumen .

3. Saluran III : petani $\rightarrow$ tengkulak $\rightarrow$ pedagang $\rightarrow$ konsumen.

4. Saluran IV : Petani $\rightarrow$ penebas $\rightarrow$ tengkulak $\rightarrow$ pedagang $\rightarrow$ konsumen.

\section{Pola Saluran Pemasaran}

Pada pola saluran pemasaran durian terdapat beberapa distribusi produk durian dari petani hingga sampai ke konsumen. Berikut distribusi pola saluran pemasaran durian dari petani di sajikan pada Tabel 2.

Tabel 2. Distribusi Saluran Pemasaran Durian.

\begin{tabular}{lcc}
\hline \multicolumn{1}{c}{ Saluran Pemasaran } & Jumlah (orang) & Persentase (\%) \\
\hline Saluran Pemasaran I & 26 & 14,6 \\
Saluran Pemasaran II & 85 & 47,7 \\
Saluran Pemasaran III & 45 & 25,3 \\
Saluran Pemasaran IV & 22 & 12,4 \\
\hline Jumlah & 178 & 100 \\
\hline Sumber: Data primer yang diolah, 2019 & &
\end{tabular}

Pada Tabel 2 terlihat bahwa distribusi pola sayuran pemasaran durian paling banyak pada pola ke II yaitu sebanyak 26 orang atau $14,6 \%$, kemudian pada saluran pemasaran III sebanyak 45 orang atau $25,3 \%$, pada saluran pemasaran IV sebanyak 22 orang atau $12,4 \%$ dan 6 orang atau $20 \%$ pada saluran pemasaran I. Pada umumnya pedagang atau pengecer disini membeli langsung ke petani dengan mendatangi petani petani durian. Hal ini juga di karenakan petani tidak memerlukan biaya dan tenaga kerja untuk memasarkan durian hanya biaya saat pemanenan buah durian terlihat pada saluran pemasaran II. Konsumen yang membeli langsung produksi buah durian dari petani, terlihat pada Pola I. Biasanya konsumen tersebut bukan asli masyarakat sekitar atau lebih tepatnya pelancong dari luar daerah yang menjadi buah tangan untuk keluarga yang ada di rumah.

Pedagang menjual buah durian lebih banyak di luar Desa Mlancu dan menjual durian di pasar pasar terdekat maupun di sepanjang jalan derah Kasembon, Pare dan sekitarnya. Seperti terlihat saluran pemasaran III tengkulak membeli durian dari langsung dari petani. Saluran pemasaran IV membeli buah durian di petani dalam jumlah besar dengan harga perbuah yang sudah menjadi kesepakatan antara penebas dan petani. Perbedaan pola saluran pemasaran ini menyebabkan adanya perbedaan tingkat harga serta marjin pemasaran yang diterima oleh masing-masing pelaku.

\section{Marjin Pemasaran, Efisiensi Pemasaran Dan Farmer Share.}

Hasil analisis marjin pemasaran, efisiensi pemasaran dan farmer's share ditunjukkan pada Tabel 3. marjin pemasaran merupakan selisih harga jual ditingkat petani terhadap harga beli konsumen. Besar kecilnya nilai marjin pemasaran pada masing-masing saluran berbeda beda, hal ini tergantung dari panjang pendeknya lembaga pemasaran yang terlibat didalamnya. Berdasarkan analisis marjin pemasaran yang telah dilakukan dapat diketahui, pada saluran I tidak adanya margin pemasaran karena petani langsung memasarkan durian ke konsumen, sehingga tidak ada lembaga pemasaran yang terlibat. Sedangkan margin pemasaran pada saluran ke II sebesar Rp 10.000,00/ buah, saluran pemasaran III Rp15.000,00/ buah dan saluran pemasaran yang ke IV sebesar 30.000,00/ buah. 
Berdasarkan analisis marjin tersebut dapat diketahui bahwa nilai marjin terbesar terjadi pada pola saluran pemasaran IV. Nilai marjin yang besar ini dikarenakan semakin banyaknya lembaga pemasaran yang terlibat didalam proses pemasaran tersebut, sehingg menambah nilai pada masing-masing pelakunya. Marjin pemasaran yang semakin besar akan berpengaruh pada harga jual ditingkat konsumen, dimana harga ditingkat konsumen akan semakin mahal.

Menurut Muslim dan Darwis (2012), suatu sistem pemasaran komoditas pertanian yang efisien itu harus memenuhi dua syarat yaitu mampu menyampaikan hasil pertanian dari produsen kepada konsumen dengan biaya yang semurah-murahnya dan mampu mengadakan pembagian balas jasa yang adil dari keseluruhan harga konsumen terakhir kepada semua pihak yang ikut serta didalam kegitan produksi dan pemasaran komoditas pertanian tersebut.

Efisiensi pemasaran juga dapat dilihat dari panjang pendeknya distibusi barang, dimana semakin panjang rantai pemasarannya maka semakin tidak efisien. Sejalan dengan pendapat Burharman (Widiastuti dan Harisudin 2013) yang menyatakan bahwa, panjang pendeknya saluran pemasaran yang dilalui oleh suatu hasil pertanian tergantung oleh beberapa faktor yakni :

1. Jarak antara produsen dan konsumen.

2. Cepat tidaknya produk rusak.

3. Skala produksi, jika skala produksi yang dihasilkan itu kecil maka tidak akan menguntungkan jika dijual ke pasar, karena akan melalui saluran pemasaran yang panjang.

4. Posisi keuangan pengusaha, produsen yang memiliki posisi keuangan yang kuat maka mereka akan cenderung memperpendek saluran pemasaran.

Tabel 3. Analisis Marjin Pemasaran, Efisiensi, dan Farmer's Share Durian.

\begin{tabular}{|c|c|c|c|c|c|c|c|c|}
\hline \multirow[t]{2}{*}{ Keterangan } & \multicolumn{2}{|c|}{ Saluran I } & \multicolumn{2}{|c|}{ Saluran II } & \multicolumn{2}{|c|}{ Saluran III } & \multicolumn{2}{|c|}{ Saluran IV } \\
\hline & $\begin{array}{l}\text { Jumlah } \\
\text { Rp/buah }\end{array}$ & $\begin{array}{c}\text { Share } \\
\%\end{array}$ & $\begin{array}{l}\text { Jumlah } \\
\text { Rp/buah }\end{array}$ & $\begin{array}{c}\text { Share } \\
\%\end{array}$ & $\begin{array}{l}\text { Jumlah } \\
\text { Rp/buah }\end{array}$ & $\begin{array}{c}\text { Share } \\
\%\end{array}$ & $\begin{array}{l}\text { Jumlah } \\
\text { Rp/buah }\end{array}$ & $\begin{array}{c}\text { Share } \\
\%\end{array}$ \\
\hline 1. Petani & & & & & & & & \\
\hline $\begin{array}{l}\text { Biaya Prod } \\
\text { Harga Jual } \\
\text { Keuntungan }\end{array}$ & $\begin{array}{c}3.364,00 \\
30.000 \\
26.635,82\end{array}$ & 100 & $\begin{array}{c}3.364,00 \\
25.000 \\
21.635,82\end{array}$ & 71,4 & $\begin{array}{c}3.364,00 \\
25.000 \\
21.635,82\end{array}$ & 65,5 & $\begin{array}{l}- \\
15.000 \\
15.000\end{array}$ & 33,3 \\
\hline 2. Penebas & & & & & & & & \\
\hline Harga beli & & & & & & & 15.000 & \\
\hline Biaya & & & & & & & $3.956,46$ & \\
\hline Keuntungan & & & & & & & $6.043,54$ & \\
\hline Harga jual & & & & & & & 25.000 & \\
\hline 3. Tengkulak & & & & & & & & \\
\hline Harga beli & & & & & 25.000 & & 25.000 & \\
\hline Biaya & & & & & 832,13 & & 832,13 & \\
\hline Keuntungan & & & & & $4.167,87$ & & $9.167,87$ & \\
\hline Harga jual & & & & & 30.000 & & 35000 & \\
\hline 4. Pedagang & & & & & & & & \\
\hline Harga beli & & & 25.000 & & 30.000 & & 35000 & \\
\hline Biaya & & & 990,66 & & 990,66 & & 990,66 & \\
\hline Keuntungan & & & $9.009,34$ & & $9.009,34$ & & $9.009,34$ & \\
\hline Harga jual & & & 35000 & & 40.000 & & 45.000 & \\
\hline $\begin{array}{l}\text { 5. Konsumen } \\
\text { Harga beli }\end{array}$ & 30.000 & & 35000 & & 40.000 & & 45.000 & \\
\hline $\begin{array}{l}\text { Total Biaya } \\
\text { Pemasaran } \\
\text { Rp/buah }\end{array}$ & - & & 990,66 & & $1.822,79$ & & $5.779,25$ & \\
\hline $\begin{array}{l}\text { Marjin } \\
\text { Pemasaran } \\
\text { Rp/buah }\end{array}$ & $\begin{array}{lll}0 & \\
\end{array}$ & & 10.000 & & 15.000 & & 30.000 & \\
\hline Efisiensi & $0 \%$ & & $2,83 \%$ & & $4,55 \%$ & & $14,44 \%$ & \\
\hline
\end{tabular}


Sumber: Data primer yang diolah, 2019

Berdasarkan hasil analisis efisiensi yang telah dilakukan, diperoleh hasil bahwa pada pola saluran pemasaran I sebesar 0\% karena petani langsung menjual kepada konsumen, saluran pemasaran II efisiensi pemasaran sebesar 2,83\%, saluran pemasaran yg ke III sebesar $4,55 \%$ dan pola saluran pemasaran ke IV sebesar $14,44 \%$. Menurut Roesmawaty (2011), ), saluran pemasaran bisa dikatakan efisien apabila, persentase Efisiensi Pemasaran (EP) sebesar $>50 \%$ maka saluran pemasaran dikatakan efisien, dan bila EP $\leq 50 \%$ maka saluran pemasaran kurang efisien. Hasil analisis efisiensi pemasaran duriam yang telah dilakukan termasuk dalam kategori efisien.

Nilai farmer share yang diperoleh dari hasil analisis yaitu pada pola saluran pemasaran II sebesar $71,43 \%$, pola saluran pemasaran III sebesar $62,5 \%$, dan pola saluran pemasaran IV sebesar $33,3 \%$ dan saluran pemasaran I menempati persentase teringgi dengan $100 \%$. Berdasarkan hasil analisis yang telah dilakukan, dapat diketahui bahwa nilai farmer share yang diperoleh termasuk dalam kategori efisien.

\section{KESIMPULAN}

1. Dari hasil penelitian pada lembaga pemasaran, diketahui terdapat empat saluran pemasaran durian di Desa Mlancu Kecamatan Kandangan Kabupaten Kediri :
a. Saluran I : Petani $\rightarrow$ Konsumen.
b. Saluran II : Petani $\rightarrow$ Pedagang $\rightarrow$ Konsumen.
c. Saluran III : Petani $\rightarrow$ Tengkulak $\rightarrow$ Pedagang $\rightarrow$ Konsumen.
d. Saluran IV: Petani $\rightarrow$ Penebas $\rightarrow$ Tengkulak $\rightarrow$ Pedagang $\rightarrow$ Konsumen.

2. Pada saluran pemasaran I tidak terdapat marjin; marjin pemasaran pada saluran pemasaran II sebesar Rp 10.000/buah; pada saluran pemasaran III sebesar Rp 15.000/buah; pada saluran pemasaran IV sebesar Rp30.000/buah.

3. Farmer's share yang diperoleh petani pada saluran pemasaran I, II, III, IV adalah $100 \%, 71,4 \%, 62,5 \%, 33,3 \%$.

4. Saluran pemasaran durian di Desa Mlancu Kecamatan Kandangan Kabupaten Kediri sudah efisien.

\section{DAFTAR PUSTAKA}

Abidin, Zainal. 2015. Aluran Pemasaran Dan Efisiensi Biaya Serta Pendapatan Usahatani Tembakau Terhadap Kontribusi Pendpatan Keluarga di Desa Brani Kulon Progo Probolinggo. Skripsi. Fakultas Pertanian Universitas Jember.

Dinas Pertanian Daerah Istimewa Yogyakarta. 2012. Standard Operating Procedure (SOP) Durian. Dinas Pertanian Daerah Istimewa Yogyakarta, Yogyakarta

Ditjen Hortikultura, 2013. Pedoman Umum Pengembangan Hortikultura Tahun 2012,Direktorat Jenderal Hortikultura Kementerian Pertanian.

Muslim, C. dan V. Darwis. 2012. Keragaan Kedelai Nasional dan Analisis Farmer Share serta Efisiensi Saluran Pemasaran Kedelai Di Kabupaten Cianjur. Jurnal Sepa. $1(9): 7-9$.

Pasaribu, A. M. 2012. Perencanaan \& Pasaribu, A. M. 2012. Perencanaan \& Evaluasi Proyek Agribisnis.Andi, Yogyakarta.

Roesmawaty, H. 2011. Analisa Efisiensi Pemasaran Pisang di Kecamatan Lengkiti Kabupaten Ogan Komering Ulu. JurnalAgrobsnis. 3(5) : 1-9.

Tjiptono, Fandi. 2014 pemasaran Jasa-Prinsip, Penerapan, dan Penelitian, Andi Offset, Yogyakarta 
SigmAgri (Journal of Social, Management, and Agribusiness)

Volume 01 No 01

Widiastuti, N. dan M. Harisudin. 2013. Saluran dan Marjin Pemasaran Jagung di Kabupaten Grobogan.Jurnal SEPA 9 (2) : $231-239$. 